\title{
A spectrum of Social Studies: Testing of the Social Reconstruction Vygotsky's Paradigm in Elementary Schools Social Studies Learning
}

\author{
I Wayan Lasmawan \\ Universitas Pendidikan Ganesha, Bali, Indonesia \\ Email: wayan.lasmawan@undiksha.ac.id
}

\begin{abstract}
In General, this research aimed to develop a new formula of ideas and hypotheses of social science education curriculum of primary school. The Development was done through the integration of the principles of social reconstruction and constructivism of Vygotsky in interactional construction. This research used the design of development research, conducted in Bali Province by involving education experts, principals, teachers, and primary school students as research samples determined by purposive-randomization. The data instruments of this research consisted of observation sheets, interview guides, questionnaires, and tests of learning outcomes. The whole research data was analyzed qualitatively with an interactive cycle model and CAR (contextuality-accuracy-relevancy) model, combined with quantitative analysis to comparatively graded the advantage of social reconstruction design with conventional learning design in social science education of primary school. The result of the study indicates that the social science competency, which allows students of primary school following the social constructivism design of Vygotsky, consisted of personal competence, sociocultural, and intellectual competence. It is also found that the relevant social science material structure to develop is when systematically organized as real pedagogical learning experiences, sociocultural, psychological, by relying on the principle of "a student as a psychological, sociocultural, and intellectual horizons reconstructions -based." Besides, the social science classroom environment is a psychological and sociocultural context that should be laid out and directed at efforts of (a) dynamization of student position from natural position to sociocultural position; (b) provide facility and personal and sociocultural mediation to students in their endeavors to reconstruct the contents, functions, and operations contained within their personalities structure.
\end{abstract}

Keywords: Internal Quality Assurance System, School Model, Context, Input, Process, Product

\section{Introduction}

When the world is confronted with the malfunctioning of social-moral mechanics, only education will survive with ethical modesty and the moral meaning of humanity. To make an educational activity "good" and "meaningful" is not an easy job and make it "a game" without meaning. Through the magic hands of education, the world's quality humans are born or vice versa (Lasmawan, 2014). Ideal education is always "anticipatory" and "prepatoric", which always refers to the future, and always prepares young people for a much better, qualified, and meaningful life (Buchori, 2001). However, from the results of reflections and criticalreflective studies of Montgemery (2012) and Dantes (2014) towards the thoughts and practices of education in Indonesia, such an ideal education has lost of its momentum, because the existing educational practice is still limited to the knowledge transfer and does not build student character.

The curriculum, which is believed to be a vital and strategic component in the entire education system, is also positioned as an effective instrument for the realization of an ideal national education because it is still thick with science-based "content-oriented." It is due to the primary school curriculum, which is currently still very thick with the paradigm of "essentialism" by setting aside open constructivism. The indication can be seen from the formulation of social knowledge understanding and the meaning of the environment for the enlargement of students in the current curriculum concept. Affirmed by Lasmawan (2014), the definition that states social studies education as "simplification of social sciences or social sciences taught in schools, is a definition developed from the view of essentialism," 
which emphasizes more on mastering "basic competencies in the scientific field" but ignoring students' socio-cultural interests and existence.

The main weakness of the essentialistic curriculum lies in the view that students are only portrayed as passive recipients of reality and truth that are ontologically outside themselves. This condition triggers the emergence of apathy and a lack of enthusiasm for students in studying social studies education. Most social science experts believe that such an essentialistic curricular inevitability can inhibit the development of academic and social modality of students, and distort their "genuine concepts" or "indigenous science" about the universe that is built and developed from the daily social and cultural experience. This condition can also distort or damage the student's self-concept, which is an essential factor for forming the student's own identity or character.

In line with the change in the paradigm of social studies learning, which began in the 1980 s, from the paradigm of "mainstream academic knowledge" to the paradigm of "transformative academic knowledge" (Banks, 1995), social learning experts and developers agreed to reconstruct the foundations of social studies curriculum in line with the development of the latest educational paradigm, namely the theory of social reconstruction (NCSS, 2002). The theory of social reconstruction is also predicted to be one of the pillars of social studies in the 21st century and shift the "habits" of behaviorism (Winataputra (2001). However, the commitment to make social reconstruction theory a new social study paradigm in Indonesia has not been supported by contextual research results. Some of the previous researches have not yet reached the other dimensions of the social studies curriculum. Considering these propositions, what objectives, content, and social studies learning should be developed based on social reconstruction theory paradigms? What standard of competency should be developed? What kind of social studies curriculum organization and structure should be developed? How should the classroom environment be developed so that social studies learning refers to the application of social reconstruction theory?

From the set of problems as described above, the purpose of this study is to "discover" and "reconstruct" curriculum ideas of social studies based on social reconstruction theory perspectives as the basis for the thought of social science curriculum. It has a "new perspective" or "alternative perspective", has a philosophical and theoretical basis that is firmly established and firmly established on the view of students as subjects. It is expected that it is more meaningful, more humanist, and more down to earth because it is based on the typical ways and contexts of student learning and in building comprehending, understanding, values, and attitudes, and grounded in the recognition that students are an integral and equal part of the overall building of the social study system. The effort is seen as a necessity, along with the sharpening of social distortions that develop in society. It is also a result of the advancement of science and technology. These conditions must be anticipated optimally and comprehensively in social studies learning as a synthetic discipline.

\section{Method}

Methodically, this research is categorized into the development research design by making the reconstruction of elementary school social studies competencies as the focus of the study. This research was conducted in Bali province, involving teachers, principals, and elementary school students from grade I to grade $\mathrm{VI}$, which was done by purposive random sampling. For this first year, research samples consisted of 18 principals, 54 senior social studies teachers, and 2,160 students. The research data was captured and mapped by several instruments, namely: observation sheets, interview guidelines, questionnaires, interrater validity, and focus group discussions. Overall research data were analyzed by using two-way variant analysis, involving qualitative analysis techniques, interactive cycle models, and quantitative analysis techniques.

\section{Results and Discussions}

\subsection{Fundamental Reconstruction of Social Study Competence Thought}

The reconstruction of social studies competence in this study was developed based on the perspective of Vygotsky's social reconstruction theory about "the nature of students 
ontology," not from the distribution of subjects in the curriculum, as commonly done. Therefore, social study competence in this study is a reflection of "student character" as personal, sociocultural, and intellectual beings. In terms of Competency-Based Curriculum and Education Level-Based Curriculum, it means "Character-Based Curriculum," rather than "Competency-Based Curriculum." "Basic" social study competence or "standard" social study competence that is typologically identified includes three dimensions of development, namely: (1) personal competence; (2) social competence, and (3) intellectual competence.

Personal competence, which is students' rights and responsibilities, is a fundamental ability related to the formation and development of a student's personality as a personal or individual being, a responsibility that has been marginalized in social studies education. The primary orientation of the formation and development of personal competencies is focused on efforts to introduce students and build their "self-awareness" as personal beings with all the uniqueness and personal wholeness that will always continue to develop. Several personal competencies of social science formulated in this study are: (1) the formation of concepts and self-understanding; (2) objective attitude towards oneself; (3) selfactualization; (4) self creativity; and (5) appreciation of religious values and attitudes in personal and socio-cultural life.

Social competence is an essential ability related to the formation and development of students' "awareness" and "personality" as social and cultural beings. The formation and development of these social competencies are adjusted to the social and cultural demands of Indonesian society today and in the future. It includes the demands of the global community.

Several necessary socio-cultural competencies that were successfully formulated in this study were: (1) understanding and awareness of the nature of oneself as a member or part of the community; (2) understanding and awareness of politeness in society; (3) communication skills; (4) interaction skills; (5) ability to cooperate; (6) pro-social attitude or altruism; (7) the ability of social participation; and (8) understanding and awareness of diversity and equality.

Intellectual Competence is the ability to think or reason based on the existence of awareness or belief in something physical, social, psychological (sensory or non-sensory), and has meaning both for oneself and others. This essential intellectual ability is related to the formation and development of students' character or identity as thinking beings that use the ability or critical thinking to receive, process, and build their knowledge, values, attitudes, and actions in both their personal and social lives.

Intellectual competence includes the ability of "indigenous" or "scientific" thinking. Standard / natural thinking (indigenous thinking) is the ability to think or "ways of thinking" that is "standard" for each student that is formed and developed in their daily lives, in order to meet the needs of their life development, both psychologically, socially and culturally at present. These standard ways of thinking need not necessarily be related to the ways of thinking of a particular discipline. Scientific thinking (scientific thinking) is the ability to think or "ways of thinking" based on scientific methods, criteria, or procedures.

Some essential intellectual competencies that can be formulated in this study are (1) critical-reflective thinking; (2) contextual thinking; (3) pragmatic thinking; (4) spatial ability; (5) understanding and awareness of time; (6) logic-mathematical abilities; and (7) historical comprehension and awareness skills. Diagrammatically, the linkages of the social study competencies can be described as follows: 


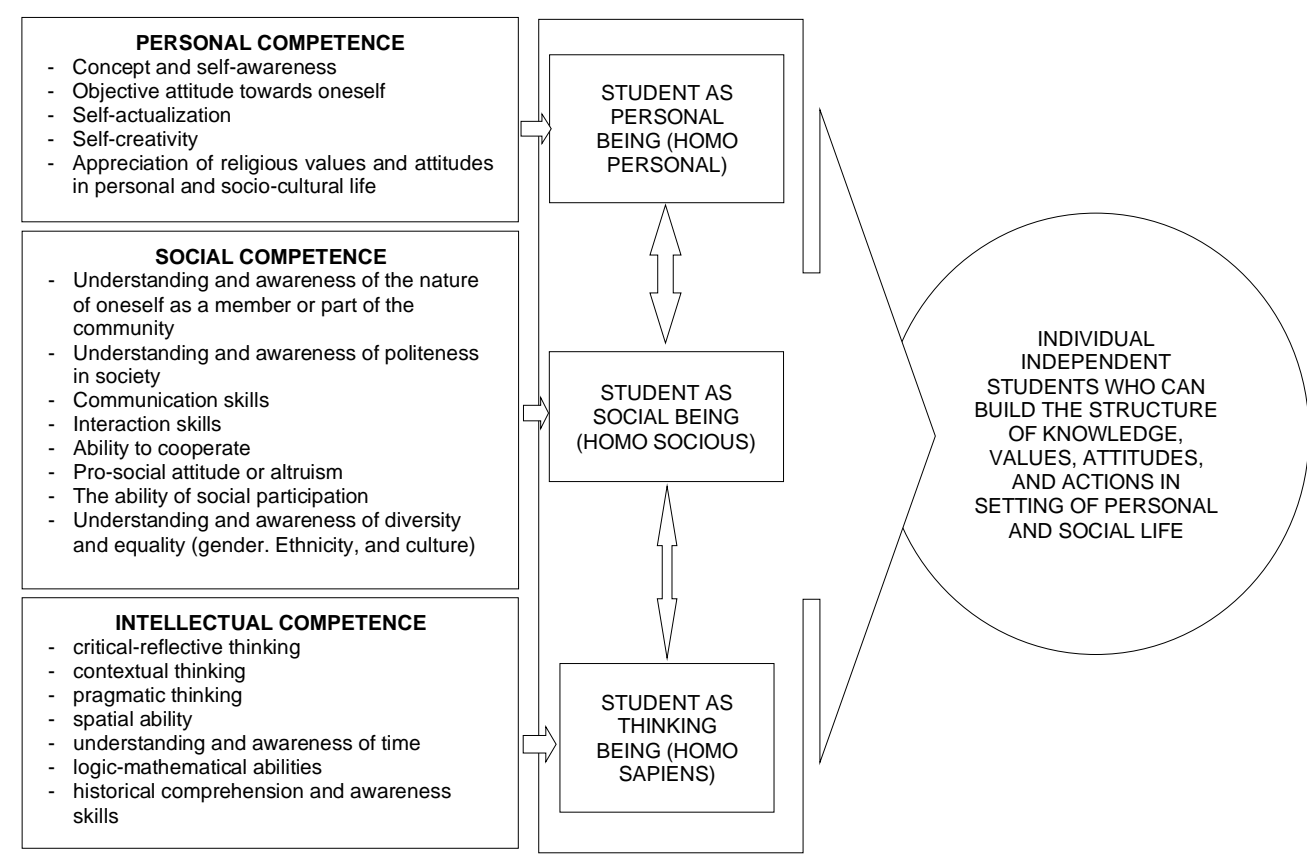

Figure 1. The linkages of the social study competencies

\subsection{Fundamental Reconstruction of for Social Science Materials Organization Pattern}

Based on the analysis of various views of students, teachers, and experts that were revealed through several instruments, several basic ideas can be formulated. They can be used as the main principles of the reconstruction of social study material organization patterns. Those principles are (1) relating to the benefits for daily life, (2) providing an understanding of nature or the environment; (3) being easy to understand and focused; (4) increasing the desire to expand or add knowledge and experience; (5) being exciting and fun; and (6) being completed by many examples that are easy to understand and taken from the environment that is already familiar with students. Based on this basic idea, how to facilitate the "comprehending or understanding" of social studies for students, as well as teachers, needs to be considered in the future concerning the formulation of elementary social study competencies.

In line with the above idea, the reconstruction of social organizing patterns and material structures should be based on the context:

Personal context, including (a) construction of students' prior knowledge; (b) the domain of student experience; (c) a network of knowledge structures or also called "conceptual ecology"; (d) the personal cultural identity of students; and (e) the domain of student psychology. This context provides the principle that the organizational pattern of the contents of the social studies curriculum must be assimilative, accommodative, and adaptive to the mechanisms and functions of students' internal (individually defined) (Bruner, 1969: 216).

The inter-personal / sociocultural context of students is a socio-cultural condition or environment in the form of "psychological tools" (psychological tools) created and used by teachers to mediate and facilitate student internal functions (cognitive, affective, and motoric) with prerequisites for students' action, in their dialectical relationships with fellow students during learning (Vygotsky, in Kozulin, 1998). This context provides the principle that the organizing pattern and structure of social studies curriculum content "must become a natural psychological function as perception, memory, and attention transformed for generating new cultural forms of psychological functions," and that "their nature becomes culturally and socially informed and organized" (Kozulin, 1998: 4, 40).

The social, cultural, and historical context of the community " are social, cultural, and historical aspects that become the daily background of students' lives. This context provides 
the principle that the organizing pattern and structure of social studies curriculum content must refer to the principle "a socially, culturally, and historically consistent excellence) (Bruner, 1969: 216).

Based on the above formulation, the reconstruction of the organizational pattern and structure of social studies material in schools should be directed at the application of the principles of "a competency-based student's psychological, socio-cultural, and intellectual horizons reconstructions." On the other hand, the organization and structure of social studies material must: (1) be understood, explained, and interpreted personally (individually defined), in terms of assimilative, accommodative, and adaptive to students' internal mechanisms and functions; (2) are "psychological tools" that are sociocultural that can be used as mediation and a bridge for students to modify and transform their internal structures and functions (cognitive, affective, and motoric) when learning interactions and communication occur (a sociocultural learning mediated); (3) has high social, cultural and historical relevance and significance (a socially, culturally, and historically relevant excellence); (4) is an interwoven or meaningfully related relation between one part of matter and another material part, becoming a totality or material unity; (5) follows a "circular", "spiral", or "tiered-cycle" pattern with an increasingly broad, rich, varied, and layered range of material; (6) allows students to be able to carry out reconstructions of the construction of knowledge, the domain of experience, and the network of knowledge structures (factual, declarative / conceptual, procedural, metacognitive, and normative / affective) that exist, become something new, and better (curriculum content must be challenging and laden with problems that can stimulate and require students to be actively involved, critically, and reflectively to find solutions); (7) builds on and aims to develop personal, social and intellectual competencies, as a basis for students to carry out reconstructions of knowledge, values, attitudes and actions independently in the context of personal and social life; and (8) able to connect, strengthen, and expand the natural and sociocultural structures of students that already exist and are formed in their daily lives in society.

\subsection{Fundamental Reconstruction of Social Study Curriculum Material Structure}

Based on the results of library studies and conclusions of empirical studies, prototypes of social material structure can be formulated which categorically should include: (1) substantive structures, (2) synthetic / procedural structures, and (3) normative/affective structures, one with each other relating to building material structure unity.

substantive structure, is interrelated and meaningful inter-curriculum relationships between various dimensions of knowledge (factual, conceptual/declarative, metacognitive) that provides students with an "equal, clear, and whole conceptual" framework within: (( 1$)$ formulating questions, (2) finding the right way to obtain and interpret data, (3) thinking, behaving, and acting, and (4) building understanding, values, attitudes, and actions, towards various realities, phenomena, problems, and cases faced in their personal and social life settings. The substantive structure of the social study is eclectically organized from "functional knowledge" or also called "spontaneous/daily knowledge," "natural science" (indigenous science), or "original concept" (genuine concept) that students build from reality and his socio-cultural experiences in people's lives (Ellis, 1998; Ogawa, 2002). Besides, it is also organized from "non-functional knowledge" or "scientific knowledge" (scientific knowledge) from the scientific disciplines to the extent that they have a level of relevance to the student's knowledge structure and can support the creation of wholeness of the interwoven theme of study.

The syntactic structure is a relationship between curriculum materials that are meaningfully interrelated among various types of procedures. It can facilitate students in terms of approaches, strategies, ways, techniques, skills, processes, and procedures in examining, testing, expanding, and building understanding, values, attitudes, and actions. It also promotes in terms of principles and criteria that must be adhered to when using or applying these approaches, strategies, methods, techniques, skills, processes, and procedures to study, test, interpret, and build understanding, values, attitudes, and his actions. 
The syntactic structure of social studies should be developed eclectically by departing from the daily syntactic structure, which students have and practice in the reality of daily life. It is specified in their ways of (a) "linking" knowledge, values, skills, and attitudes existing in themselves with the new experiences they have gained, and (b) "building" knowledge, values, skills, and attitudes from their daily experiences. Besides, it should also be developed by departing from the scientific syntactic structure (social and non-social), by considering its relevance to the syntactical structure of students; be based on consideration of possible applications by students; be following the characteristics of the field of social studies; and has been adapted, modified, specifically for the benefit of social studies learning in the world of schooling.

As the substance of the social study curriculum, the use of scientific syntactic structures is not intended to train students towards mastering approaches, strategies, methods, techniques, skills, processes, procedures, and scientific principles and criteria; but rather an effort to strengthen and expand the basic "operations" contained in the structure or organization of student actions, namely: (1) cognitive operations, or commonly called "cognitive processes," or "skills intellectual "; (2) meta-cognitive operations, "cognitive strategies," or also commonly called "metacognitive strategies, executive functions or control structures"; "Self-management abilities" and/or "mathematical activities"; (3) effective surgery; and (4) psychomotor operations (physical skills). Diagrammatically, the detailed reconstruction of the basic structure of social studies material in the context of schooling can be described as follows:

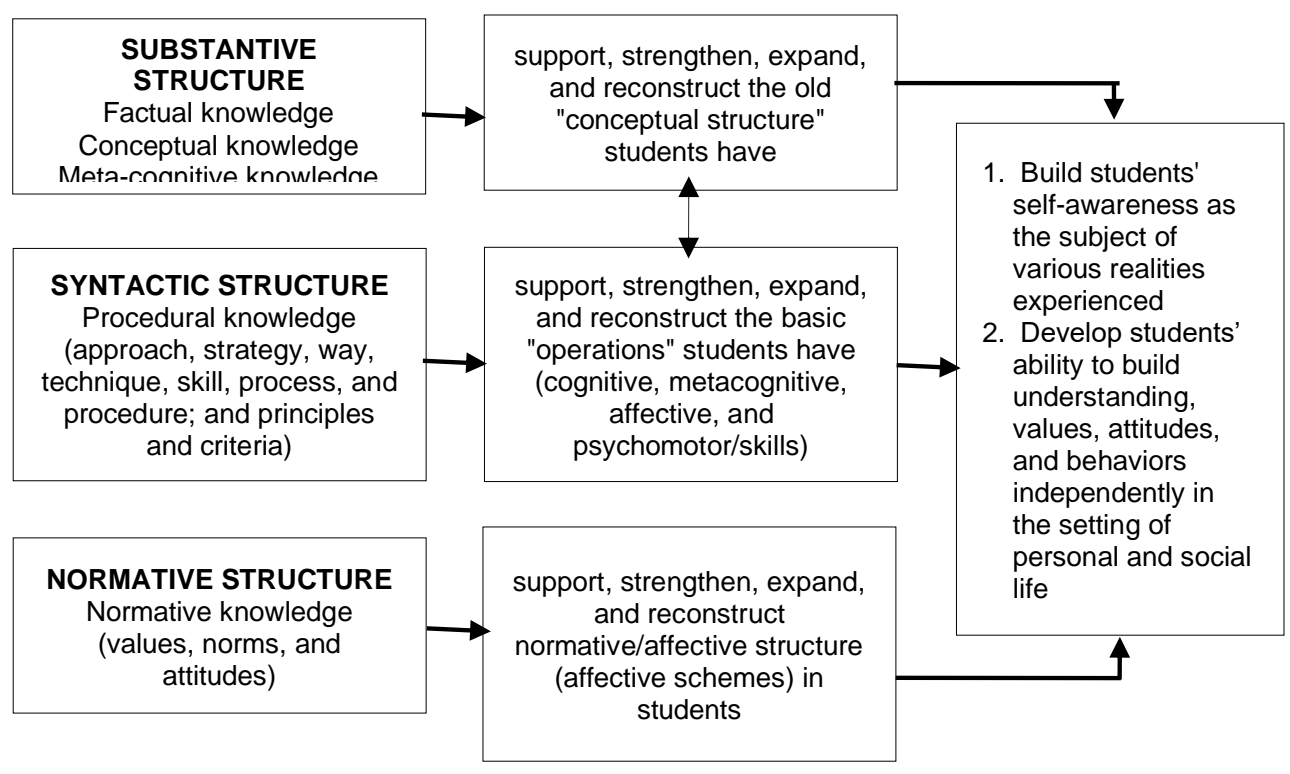

Figure 2. the related reconstruction of the basic structure of social studies material in the context of schooling

The normative/affective structure or "affective scheme," is intended as a relationship between curriculum materials that are meaningfully interrelated among various normative or intellectual contents. This normative/affective structure gives students a framework for thinking, behaving, and acting following their values, norms, and attitudes based on their worthiness in terms of ethical, cultural, moral, religious, scientific, and aesthetic standards. It is eclectically developed based on values, norms, and attitudes contained in religion, culture, law, morals, knowledge, ethics, and aesthetics which: (1) become general or joint agreements, among the broader communities and social study communities; and (2) are owned and become the students' reference in thinking, behaving, and acting in the setting of their personal and socio-cultural life. Both normative/affective structure content types must be synergistically able to support, strengthen, expand, and reconstruct the 
normative/affective structures in students. Concerning the content of the normative/affective structure, which is still controversial in the "taboo area", until now, there has been no agreement among social science experts in Indonesia, nor has there been any research done and supported its significance. Even it has not yet considered is included in the reconstruction of the social curriculum content structure.

Organizing the contents of the social study curriculum as a systemic wholeness of meaningful learning experiences for students, which is eclectically developed in line with the principle of continuity and interactional between students' subjective experiences that are built from a variety of personal and socio-cultural backgrounds in everyday life with scientific experiences that are daily built from the background of class or school life. The meaningfulness of the contents of the social study curriculum can be achieved if it is organized and developed based on the principle of intertwining and thematic integrity among substantive, syntactic, and normative structures into a totality or unity of curricular content. It is also can be achieved when it is positioned as mediation and facilitation for students to carry out "functional links" and "internal reconstructions" of their natural and socio-cultural ecological structures; and not as a collection of separate information units which must be mastered by students for scientific purposes only.

The content structure of the social study curriculum is intrinsically built based on the principle of "a student's psychological, sociocultural, and intellectual horizons characterbased reconstructions." It also consists of the contents contained in (a) "natural and sociocultural structures" of students, (b) "socio-cultural-historical structure" of the community, and (c) "scientific structure." A scientific approach that is too strong or excessive in organizing the contents of the social studies curriculum poses a danger for the occurrence of material that is very abstract, verbalizes, academic, and sterile to students' natural and socio-cultural desires and interests to better understand and interpret themselves and their communities. It also can damage students' "natural and socio-cultural structures," weaken students' academic self-concepts and release students from their sociocultural reality, which becomes their establishment and implementation context.

\subsection{Fundamental Reconstruction of Social Study Class Arrangement}

Based on the perspective of social reconstruction theory, classroom learning must be able to function effectively as a "psychological context," and a "socio-cultural context" for each student. It purposes to create personal and socio-cultural meanings, as the creation of psychological / socio-cultural and social-cultural conditions/conditions that can stimulate the possibility of students to interact or link between content and substantive, syntactic, and normative structures that are systematically organized in the curriculum with substantive, syntactic, and normative content and structures that students have. In other words, the nature of the creation of a social studies classroom climate is not limited to the creation of classes that are psychologically interesting, fun, or invading; or sociocultural interactive, communicative, and transactive for students.

In order to create such a classroom learning environment, the structuring pattern is focused on creating classrooms that can help and facilitate students to shift their position dynamically and flexibly from "natural position" to "sociocultural position," vice versa. It is also expected to facilitate and mediate students so that construction and the reconstruction of the "contents," "operations," and "functions" (organization and adaptation) contained in its internal structure through various experiences, activities, and materials learned occurs. From the perspective of social reconstruction theory, each gives different attention. The perspective of psychological/personal social reconstruction theories focuses on the importance of "delivery systems," "packaging of teaching materials," and "creation of learning conditions" following the characteristics of learning objectives. The perspective of interpersonal/sociocultural social reconstruction theory focuses on the importance of "mediating agents" namely: "teachers, material tools and psychological tools" in the process of interaction, transactions, and communication of subjective or inter-subjective meanings as a precondition for their work " psychological functions "students. The perspective of sociological social reconstruction theory focuses on the importance of "socio-cultural class" 
that allows students to perform various forms and qualities of interaction and transaction of subjective or inter-subjective meanings. Diagrammatically, the pattern of the social class instruction, which is following the spirit of social reconstruction theory, can be described as follows:

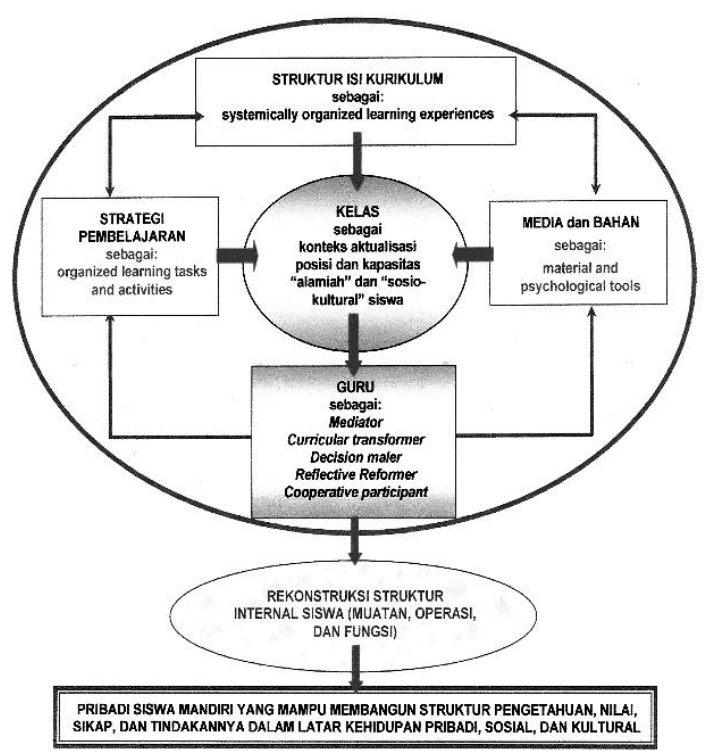

Figure 3. The pattern of the social class instruction which is following the spirit of social reconstruction theory

In the overall pattern of structuring the social class environment, the teacher factor is very contributive. Based on the perspective of the social reconstruction theory, two reasons can be stated. The first is the presence of teachers that are still needed in instructional activities, no matter how small the role will be played, because the teacher is a leader who is recognized or not, said Dewey as a person "wider and deeper knowledge and matured experience. " The second is, even though students are recognized as having innate abilities, a student also has certain weaknesses and limitations which do not allow everything to be done and solved by themselves, through internal functions and operations. That each student, according to Vygotsky, has a "Zone of Proximal Development," which is a region that distinguishes between what students can do themselves (potential development zone), with what students can do with the help of others (actual development zone). The teacher's role in this connection is as: mediator, curricular transformer, decision-maker, reflective reformer, and cooperative participant in student learning activities.

Based on observation and interview, a preposition can be formulated that paradigmatically teachers, learning strategies, materials and learning media function as mediators of student learning activities, because they: (1) moderately provide "intellectual links" between students' curriculum content structures and internal structures ; (2) allow students to be able to carry out reconstructions of loads, functions, and operations in their internal structure; and (3) facilitate and bridge students to be able to cross the limits of their potential abilities to the limits of actual abilities.

\subsection{Discussions}

Based on the contextual findings, reconstruction, and research conclusions, it appears that social study is a pedagogical, socio-cultural, and psychological vehicle that aims to facilitate and mediate each student's endeavor to shape his identity; strengthen, expand, and reconstruct "natural construction" and "socio-cultural" which are built from daily experience, and used in interpersonal relations in society. The fundamental competencies of social studies are more relevant, meaningful, and have personal significance for students if 
they are directed towards the formation and development of concepts and selfunderstanding; objective attitude towards oneself; self-actualization; self creativity; and appreciation of values and religious attitudes in students' personal and social lives.

The fundamental competencies of social studies are more relevant, meaningful, and have socio-cultural significance for students if they have directed towards the formation and development of several competencies. Those competencies are understanding and awareness of the nature of oneself as a member or part of society, understanding and awareness of manners/manners in social life, communication skills, social interactions, collaborate with others, pro-social attitudes or altruism, social participation, and students' understanding and awareness of diversity and equality (gender, ethnicity, and culture). The fundamental competencies of social studies are more relevant, meaningful, and have intellectual significance for students if directed towards the formation and development of critical-reflective thinking skill, contextual thinking, pragmatic thinking; spatial ability (geographical skills), understanding and awareness of time, logic-mathematical ability, and understanding and historical awareness of students. They are not as a collection of separate intellectual abilities and skills derived from competencies in the field of scientific studies contained in curriculum subjects.

Social studies learning can be a pedagogical, sociocultural, and psychological vehicle for students, if: (a) students can create personal and sociocultural meanings through continuous interaction, dialogue, and negotiation of subjective and intersubjective meanings; (b) it arouses students' critical-reflective motivation and awareness to nurture and enhances their best natural, sociocultural talents, interests, and desires; (b) it is based on mutual trust, mutual respect, and strong partnerships between students and teachers; (c) it provides opportunities and challenges for students to express themselves and develop their independence naturally or authentically. On the other hand, social studies learning activities, materials and media are more meaningful for students, if they are interpreted as "learning media" and "communication, interaction, negotiation, and interpersonal dialogue" which provide "structural and functional links" for students to carry out reconstructions of their natural and socio-cultural structures, which are more than just "instruments for delivering curriculum content" for teachers.

\section{Conclusion}

Based on the results of contextual studies and conceptual and textual studies, as stated above, several concept-prepositions can be formulated as conclusions, namely:

First, student competencies developed in social studies are ontologically the embodiment of students' natural and sociocultural character and capacity as personal, social, and intellectual beings. Epistemologically, it is built and developed in a variety of personal and socio-cultural daily life settings as the context for its formation. Axiologically used in building personal and sociocultural awareness of students, and in building understanding, values, attitudes, and actions in society, based on the personal and sociocultural background.

Second, students' competencies in the context of social studies which are contextually, conceptually, and philosophically can be formulated including: (1) personal competencies: self concept and understanding, objective attitude towards themselves, selfactualization, self-creativity, and appreciation of values and religious attitudes in personal and social life; (2) social competence: understanding and awareness of the nature of oneself as a member or part of the community, understanding and awareness of manners in social life, communication skills, social interaction skills, ability to cooperate with others, pro-social or altruistic attitudes, social participation skills, and understanding and awareness ability of diversity and equality (gender, ethnicity, and culture); and (3) intellectual competence: critical-reflective thinking, contextual thinking, pragmatic thinking, spatial ability (geographical skills), understanding and awareness of time, logic-mathematical ability, and historical understanding and awareness.

Third, content organization pattern of social study curriculum is not developed based on the organizational pattern of the contents of the disciplinary structure. However, it is 
organized systemically as learning experiences that are pedagogical, socio-cultural, psychological based on the principle of "a student's psychological, socio-cultural, and intellectual horizons character-based reconstructions," which is characterized by: (1) contextual - personal and socio-cultural; (2) meaningful thematic intertwining with one another as a totality or unity of curriculum content; (3) developing students' personal, social and intellectual competencies; and (4) enabling the reconstruction of the contents, operations and internal functions of students, as the essence of the social studies curriculum content organization pattern of social reconstruction theory.

Fourth, the social class environment is a psychological and socio-cultural context that must be arranged and directed at: (a) dynamizing students' positions from natural positions to socio-cultural positions; (b) providing personal and socio-cultural facilitation and mediation to students in each of their endeavors to carry out reconstruction of the contents, functions, and operations in the internal structure.

\section{References}

Abijhani, P.V. (2006). The Social Studies Breaking Concepts. tersedia di: www.spartan.ac. brocku.ca/ Iward/ dewey/dewey1910.html [diakses tanggal 10 Januari 2006].

Banks, J.A. (1995). Transformative Challenges to the Social Sciences Disciplines: Implications for Social Studies Teaching and Learning. Theory and Research in Social Education, XXIII(1), 2-20.

Bruner, J.S. (1969). After John Dewey, What?. dalam R.D. Archambault. (2d). Dewey on Education: Appraisals. New York: Random-House. 211-227.

Bruner, J.S. (1978). The Process of Education. Cambridge: Harvard University Press.

Buchori, M. (2001a). Pendidikan Antisipatoris. Yogyakarta: Kanisius.

Cornbleth, C. (1991). Research on Context, Research in Context. dalam Shaver, J.P. (ed). Handbook of Research on Social Studies Teaching and Learning. New York: Macmillan Publishing Company. 265-275.

Depdiknas. (2006). Kurikulum Tingkat Satuan Pendidikan. Jakarta: Depdiknas.

Dewey, J. (1964). Democracy and Education: An Introduction to the Philosophy of Education. New York: Mcmillan Co.

Ellis, A. (1998). Rational emotive behavior therapy and its applications to emotional education. In A. Ellis \& S. Blau (Eds.), The Albert Ellis reader: A guide to well-being using rational emotive behavior therapy (pp. 253-260). New Jersey: Citadel Press.

Farisi, M.I. (1997). Pengembangan Pembelajaran Pendidikan IPS-SD Berdasarkan Penggunaan Konsep Siswa. Tesis S2, Bandung: PPS IKIP Bandung.

Gagne, R.M. (1977). The Conditions of Learning. New York: Holt, Rinehart \& Winston.

Hasan, S.H. (2002). Pendidikan Sering Hanya Sebatas Transfer IImu: Tidak Membangun Karakter Siswa dan Nilai Sosial. Pikiran Rakyat, 29 Nopember 2002.

Kozulin, A. (1998). Psychological Tools: A Sociocultural Approach to Education. London: Harvard University Press.

Lincoln, Y.S. \& Guba, E.G. (1985). Naturalistic Inquiry. London: SAGE Publications.

NCSS. (2004). Science-Technology-Society (STS) in Social Studies: Position Paper. Washington DC: NCSS.

Nitko, V.S. (1918). The Revolution of Social Concept. USA: Agraware Ltd.

Ogawa, M. 2002. "Science As the Culture of Scientist: How To Cope with Scientism?". [Tersedia] Online: http://sce6938-01.fsu.edu/ogawa.html

Winataputra, Udin, S. 2001. Model-model Pembelajaran Inovatif. Jakarta Pusat: Direktorat Jenderal Pendidikan Tinggi Departemen Pendidikan Nasional. 